\section{Pacientes estandarizados en la formación de habilidades clínicas, en educación médica de pregrado}

\section{Standardized patients in clinical skills training in undergraduate medical education}

Sr. Editor:

Hemos leído con mucho interés el Artículo de Revisión de Corvetto et al, recientemente publicado en Revista Médica de Chile ${ }^{1}$. Deseamos comentar nuestra experiencia y apreciaciones respecto a simulación clínica en docencia de pregrado en la Facultad de Medicina de la Universidad de Chile, tratando de aportar una visión complementaria a la expuesta por los autores aludidos.

Entendemos que simulación clínica se refiere a una amplia gama de metodologías y que, entre ellas, se destaque el uso de los así llamados simuladores que, tal como expone el artículo, pueden ser catalogados de acuerdo a su complejidad tecnológica. Tales equipos han sido desarrollados para adquirir competencias en escenarios clínicos determinados y específicos, y emulando condiciones que por razones fundamentalmente de seguridad del paciente, son complejas de enseñar con pacientes reales. Se trata generalmente de procedimientos potencialmente complejos, molestos o riesgosos, que necesitan de un entrenamiento con una curva de aprendizaje que supone ciertos errores y una cantidad de repeticiones bajo supervisión que preceden a la adquisición del dominio de la técnica. Por otro lado, hemos de notar las dificultades que tienen los estudiantes de la salud respecto a aspectos comunicacionales, relacionales y de entrevista clínica, en general poco tratados en los programas curriculares actuales. Conocido es que la mayor parte de los errores en el desempeño de los profesionales de la salud se relacionan con la comunicación. Aquellas dificultades son claramente percibidas por nuestros pacientes, toda vez que declaran, por ejemplo, "no me quedó claro lo que el doctor me indicó" o que el profesional que lo atendió "no me miró en ningún momento" o "no me dijo cuando tenía que volver".

A nuestro entender no hay condición más importante que la relación humana y profesional -más allá de lo técnico- entre el profesional de la salud y el paciente, considerado como persona, muchas veces enfermo, que requiere de toda nuestra ayuda y compasión.
Por ello, nuestros esfuerzos en el recién creado Centro de Habilidades Clínicas de nuestra Facultad se concentran en reponer o reintegrar en el currículum de pre y postgrado de nuestras carreras del área de la Salud, aquellas competencias -conocimientos, habilidades y destrezas- que comprenden los aspectos relacionales. Nuestro trabajo se ha centrado en formar pacientes simulados o estandarizados representando diversas situaciones clínicas, para que nuestros alumnos desarrollen habilidades complejas lo más cercanas posible a situaciones reales, aprendiendo técnicas de entrevista, de comunicación y de relaciones interpersonales bajo condiciones controladas. La amplitud de este proyecto incluye a todas las carreras del área de la salud y, en algo que frecuentemente es obviado en la formación de pregrado, también considera las relaciones y el trabajo conjunto de los distintos integrantes del equipo de salud.

Los pacientes estandarizados son personas de distintos oficios y condiciones socioculturales, no necesariamente actores, ni pertenecientes al área de la salud, entrenados para representar roles que emulan situaciones de atención de salud, de acuerdo a un guión preestablecido ${ }^{2}$. Tales roles los elaboran docentes clínicos de las más variadas áreas de las ciencias de la salud, de acuerdo a las necesidades académicas. En ocasiones también es posible que pacientes reales acepten este desafío al participar en situaciones clínicas simuladas y permitan ser examinados bajo condiciones controladas.

La evaluación formativa del enfrentamiento clínico de los alumnos con pacientes simulados puede estar a cargo del académico, del mismo paciente estandarizado o incluso de los mismos alumnos, a través de actividades de retroalimentación y debriefing. El Centro de Habilidades Clínicas dispone de académicos formados en esta metodología, así como de una infraestructura especialmente construida para la supervisión de escenarios clínicos y su registro en audio y video para revisiones posteriores, tanto para la atención de pacientes ambulatorios y salas de hospital o urgencia.

Ciertas situaciones complejas, como una depresión grave, un paciente especialmente molesto y desafiante, o comunicar el fallecimiento de un familiar son todo un reto, tanto para el paciente estandarizado que debe representar el rol, como para el alumno. Sin embargo, exponer a nuestros 
estudiantes a tales situaciones en un ambiente controlado los prepara mejor para enfrentar similares circunstancias en la vida real.

Creemos que la complejidad de la simulación clínica debe considerarse no sólo tomando en cuenta la tecnología a ocupar en ella, sino también las condicionantes que exponen al alumno en lo clínico y vivencial.

\section{Iván Solís ${ }^{1,2}$, Sergio Bozzo ${ }^{1,3}$,} Natasha Kunakov ${ }^{1,4}$

${ }^{1}$ Centro de Habilidades Clínicas, Facultad de Medicina, Universidad de Chile. ${ }^{2}$ Departamento de Medicina, Hospital Clínico Universidad de Chile.

${ }^{3}$ Departamento de Medicina, Hospital San Juan de Dios, Campus Occidente Facultad de Medicina Universidad de Chile. ${ }^{4}$ Departamento de Educación en Ciencias de la Salud, Facultad de Medicina, Universidad de Chile.

\section{Referencias}

1. Corvetto M, Bravo MP, Montaña R, Utili F, Escudero E, Boza G, et al. Simulación en educación médica: una sinopsis. Rev Med Chile 2013; 141: 70-9.

2. Myung SJ, Kang SH, Kim YS, Lee EB, Shin JS, Shin HY, et al. The use of standardized patients to teach medical students clinical skills in ambulatory care settings. Med Teach 2010; 32: e467-e470.

Correspondencia a:

Dr. Iván Solís Opazo

Departamento de Medicina Norte. Hospital Clínico Universidad de Chile.

Santos Dumont 999, Santiago, Chile.

Teléfono: +562-29788242

E-mail: isolis@hcuch.cl 